\title{
South African public opinion on the state of urban transport: an appraisal of the achievement of policy objectives
}

\author{
G. J. Heyns \& R. Luke \\ Department of Transport and Supply Chain Management, \\ University of Johannesburg, South Africa
}

\begin{abstract}
Democracies require public participation and depend on having an engaged and well-informed and responsive electorate. Even though public participation is entrenched in the South African Constitution (1996), service delivery protests over recent years seem to indicate that the citizens do not believe that their concerns are being considered. Public transport policy in South Africa is currently described by a number of documents, mainly the White Paper on National Transport Policy, the National Development Plan and, more recently, the National Transport Masterplan (NATMAP). An annual survey of 1,000 South Africans is conducted to gauge opinion on transport related matters. The purpose of this paper is to consider the latest 2015 survey results and compare public opinion on urban transport with the current public transport policies and initiatives to determine the extent to which the public believe the policy objectives are being met. The results show that transport policy is relatively strongly aligned with the urban transport needs of the population however South Africans are still very concerned about the state of transport in the country, ranking it as their third highest concern after education and health. In practice, although the policies intend to address these issues, accessibility, availability, reliability, safety and affordability are not yet considered to be at satisfactory levels. The paper highlights the general public's major areas of concern regarding public transport, which should therefore be flagged as priorities by local and national government. This research makes a novel contribution in being the only annual public opinion survey (and therefore trend barometer) on transport matters in South Africa.

Keywords: urban transport, transport policy, public opinion, South Africa.
\end{abstract}




\section{Introduction}

"In a democratic system of government, the ultimate political authority rests in the hands of the people" [1]. It is thus crucial that the government take cognisance of its citizens' needs and opinions. Even though public participation is entrenched in the South African Constitution (1996), service delivery protests over recent years seem to indicate that the citizens do not believe that their concerns are being listened to.

In a representative democracy it is the responsibility and obligation of elected government officials to ensure that the needs of their citizens are met. There are various ways in which public representatives can attempt to determine the views of its citizens, including public opinion polls [1]. The purpose of this paper is to consider the latest State of Transport Opinion Poll South Africa (STOPSA) on transport, conducted by the Institute of Transport and Logistics Studies (Africa) across South Africa in 2015 and compare public opinion on urban transport with the current public transport policies and initiatives to determine the extent to which the public believe the policy objectives are being met.

\section{Literature review}

Public opinion surveys are increasingly regarded as one of the most important communication links between government and its electorates in most modern democracies [3]. According to Lee and Odugbemi [4] politicians and public officials should not wait until ordinary citizens are incited to public action, but rather listen to the opinions of ordinary individuals which can serve as a regular, indispensable resource to achieve the objectives of equity, efficiency, responsiveness, and representation.

According to Levasseur [5] public opinion plays a critical role in a democracy, as democracies are, by nature, responsive to the people and a greater understanding of public opinion should lead to improved democratic governance. This view is supported by Chudowskya and Kuziob [6] who state that by ignoring public opinion, not only will it have an impact at the election polls, but could also indicate that government is indifferent to the opinions of its citizens. Lewis and Hildreth [7] support this and state that public opinion polls are an essential method of obtaining public input into the political decision making process as it is a more direct way for society to express policy preferences.

Public opinion surveys are important tools in any government's planning processes. According to Geer et al. [8], surveys of public opinion is perceived as the most reliable indicators of gauging what the public is thinking. Hensher and Daniels [9] state that opinion polls are indicators of consumer or business sentiment and can be used over time to measure consumer confidence on aspects such as purchasing decisions, employment, capital investment and official interest rate adjustments. Opinion polls can thus potentially inform the future direction of the economy.

In South Africa, public participation is entrenched in the Constitution [2] and is aimed at ensuring that the South African government remains accountable to the 
public and transparent in its actions. This implies that the ruling government needs to take public opinion into account at all levels of decision-making. However, the high number of service delivery protests in South Africa in recent years appears to indicate that the current government is out of touch with the opinions of the South African citizens and the citizens, in turn, do not feel that the government is delivering on their promises or taking the needs of the citizens into account in their planning or service delivery.

Opinion polls are important as they provide information on what people feel and want, but also on their levels of satisfaction with the current level of infrastructure and service provision. Accurately gauging public opinion is therefore a critical part of the foundation for ensuring better decision making and maintaining credibility. Polls therefore play a critical role, not only in impacting government policy and serving as a critical communication link between governments and citizens [10], but is also an indicator of the relative satisfaction or dissatisfaction with government's delivery on their election promises and mandates.

In South Africa, transport opinion polls are not common. The National Household Travel Surveys were conducted in 2003 and 2013 and contained a few questions on transport users' opinions on service quality, but was mainly focused on travel patterns $[11,12]$. Aside from these examples, little else could be found in the literature on the public's opinion on transport related issues, other than the World Bank's Logistics Performance Index [13], which provides some opinions on transport matters, albeit logistics related.

It is evident from the above that public opinion should play a critical role in public policy formulation and various governments use transport opinion polls to inform their decision making process. In South Africa, it is postulated that the government is "out of touch" with public opinion [14, 15]. As a result, it is likely that policies are not always geared to meeting societies' needs. The purpose of this paper is to gauge public opinion on transport issues and analyse these in terms of government's stated transport policy objectives to determine whether policy objectives and societal requirements are appropriately aligned.

\section{South African public transport policy}

The White Paper on National Transport Policy [16] set the scene for transport policy in South Africa, shortly after the first democratic elections, in the mid1990s. The vision for South African transport set at the time was for a system which would: "Provide safe, reliable, effective, efficient, and fully integrated transport operations and infrastructure which will best meet the needs of freight and passenger customers at improving levels of service and cost in a fashion which supports government strategies for economic and social development whilst being environmentally and economically sustainable" [16].

The policy was determined after extensive consultation with industry roleplayers; users, service providers, regulators, other government agencies, consultants and other affected parties. Whilst the policy formulation process was considered to be broad-based, even the policy acknowledged at the time that the 
"high costs, inefficiencies, the high and often unrealistic expectations, and the limited financial resources of Government, mean that it is unlikely that it will be possible to meet all demands in respect of transport services" [16].

It is evident now that it is unlikely that this vision is achieved, as goals are too broad and possibly too idealistic. Urban LandMark [17] state that trying to give people access to markets, "which improves the potential for sustainable poverty alleviation" has been a key planning imperative "for cities in developing for decades". "And yet it has not happened to any great extent, at least not in South Africa" [17].

The National Development Plan (NDP) [18] is a relatively new policy framework that intends to improve South Africa's economic growth prospects. Its objectives are reducing poverty and inequality in the country by 2030 . Its economic objectives are job creation, a more equitable distribution of wealth and improving education [18]. In terms of transport, the NDP states that investment should ensure that the sector serves as a key driver in empowering South Africa in its people;

- Bridge geographic distances affordably, foster reliably and safely so that all South Africans can access previously inaccessible economic opportunities, social spaces and services.

- Support economic development by allowing the transport of goods from points of production to where they are consumed. This will also facilitate regional and international trade.

- Promote a low-carbon economy by offering transport alternatives that minimise environmental harm [18].

In terms of urban transport, the NDP states that "providing suitable means for the safe, efficient and cost-effective transport of people and goods is crucial" [18]. To create workable urban transit solutions, the NDP requires that investment in public transport is increased and existing public-transport policy issues are resolve, transport management is devolved to the local government, incentives are provided for public transport use, road infrastructure is improved and the commuter fleet is renewed.

Specifically, in the period 2010-2015, the NDP states that streamlining of assets and institutional arrangements for public transport (including the powers and functions of role players) should be improved, the commuter fleet should be renewed and transport planning, led by central government, should be in place to formulate credible long-term plans for transport that synchronises with spatial planning and aligns the infrastructure investment activities of provincial and local government [18]. Already, in 2016, it is clear that the commuter fleet has only been partially renewed, public transport arrangements have not yet been streamlined and the planning process has not yet been finalised. Given this, it seems unlikely that the medium term (2016-2020) goals of ensuring that, guided by plans for urban form, growth should be transit led, will be met.

Whilst the NDP considers national growth and development in general, the National Transport Masterplan (NATMAP) [19] seek to address specific transport issues and develop a long term plan for transport development in South Africa to 
2050. Although this process was started some years ago, the document was still under review in 2015.

NATMAP's vision for 2050 is transport that "meets the needs of freight and passenger customers for accessible, affordable, safe, frequent, high quality, reliable and seamless transport operations and infrastructure. It will do so by continuously upgrading infrastructure and services ahead of demand, as well as in an innovative, flexible and economically and environmentally sustainable manner. Transport will support and enable government strategies, particularly those for growth development, redistribution, employment creation and social integration, both in South Africa and the southern African region" [19].

NATMAP 2050 sets out ten objectives to facilitate meeting this vision. Nine of those ten impact urban transport and are stated as:

- "A much improved sustainable public transport system that is appropriately funded, with a reduction in the subsidy burden, with better and safer access, more frequent and better quality services and facilities to an agreed standard;

- Greater mobility options particularly for those who do not have a car;

- Non-motorised transport network development;

- A transport system that promotes better integration between land use planning and transport planning to encourage densification and sustainable development in supporting high volumes of travel required for public transport;

- Better infrastructure, better maintained road and rail network, with proper management and operations practices, that links and provides interchange opportunities for different modes of transport;

- A transport system that is consistent with the real needs of people living in different parts of South Africa and with differing abilities to afford travel;

- A transport system that charges the traveller a fair reflection of the costs of making a journey or transporting a product, financially, socially and environmentally;

- A transport system that supports focused funding of transport priorities;

- A transport system that has sufficient human capital to drive the vision of transport" [19].

An analysis of this vision indicates that this is largely aligned with the vision of the White Paper as well as the requirements on the NDP. Given that the visions for transport have remained relatively consistent since the White Paper in 1996, with emphases on safety, mobility, meeting freight and passenger needs, costeffectiveness and affordability and improving the quality of infrastructure and operations; public opinion polls can provide an indication of whether the public believes that the objectives are or can be met and, if they are being met, the extent to which this is happening.

\section{Research methodology}

The purpose of the ITLS (Africa) State of Transport Opinion Poll South Africa (STOPSA) is to gauge community confidence regarding transport on a regular 
basis across South Africa. STOPSA is an annual telephone survey of at least 1,000 South Africans, aged 18 years and over, and is representative of all South African provinces.

A two-phase approach was followed during the STOPSA 2015 survey. In Phase 1, a list of 5,000 prospective respondents were randomly selected which is representative of the geographical and socio-demographic (provincial, ethnic and employment status) characteristics of the population in South Africa. In Phase 2, respondents were randomly selected from the identified list and asked to participate in a computer aided telephonic interview (CATI). The random and quota sampling resulted in a total of 1,090 South Africans that were willing participants in the survey. The telephonic survey was conducted by a market research company, using trained interviewers. Although a larger sample would reduce the sampling error, the sampling size indicates a trade-off with the costs of conducting the survey.

The research instrument provided for demographic information such as location, age, gender and employment status to ensure representative geographical and social-demographic sampling. Of the sample population, $50.5 \%$ are males and $49.5 \%$ are females. The majority of the respondents, $55.6 \%$ are between the age of 18 and 40 years. The majority of the respondents, $62.8 \%$, are employed in some capacity, compared to the $18.3 \%$ who are unemployed.

Due to the population size, totaling approximately $44 \%$ of South Africa's population and respondents, the results from Gauteng (25\%) and Kwazulu Natal (19\%) significantly influence the national results. The results from smaller provinces such as the Northern Cape, Free State and North West, with a total of approximately $15 \%$ of the total population, could be more variable due to the small sample size.

The demographic profile from the survey approximated a relatively accurate reflection of the South African demographic profile [20].

\section{Research results}

The key public transport areas that were tested included assessing whether the public considered transport to be a national priority, what the highest priority issues in transport are, and what changes are experienced in transport conditions, locally as well as nationally. Other issues that were also tested pertained to infrastructure funding (e-tolls), law enforcement and public transport use.

In the survey, education was identified as the highest priority issue in South Africa today, it was nominated by more than $70 \%$ of the respondents as one of the three highest priority issues. Health and transport were the other two main areas of importance.

The survey indicated that transport is still the third highest overall priority in South African society today, comparable to the results of the first STOPSA survey conducted in 2012 [21]. This ranking indicates that transport is still regarded as critical despite the attention it has received in numerous policy initiatives, including 2012's National Development Plan. 


\begin{tabular}{|l|c|}
\hline \multicolumn{1}{|c|}{ Priority lssue } & Rating \\
\hline Education & 82.0 \\
\hline Health & 80.7 \\
\hline Transport & 77.6 \\
\hline Safety and secruity & 75.7 \\
\hline Housing & 75.5 \\
\hline Law and Order & 75.1 \\
\hline Economy & 74.6 \\
\hline Employment & 73.4 \\
\hline Environment & 73.0 \\
\hline Infrastructure & 72.6 \\
\hline Social Issues & 72.0 \\
\hline
\end{tabular}

\begin{tabular}{|c|c|c|}
\hline $\begin{array}{l}\text { Very Low Priority } \\
(0-20)\end{array}$ & $\begin{array}{l}\text { Indififerent } \\
\text { (30-80) }\end{array}$ & $\begin{array}{l}\text { Very High Priority } \\
(90-100)\end{array}$ \\
\hline $23.6 \%$ & \multicolumn{2}{|c|}{$\overline{70.8 \%}$} \\
\hline $25.0 \%$ & \multicolumn{2}{|c|}{$69.7 \%$} \\
\hline $30.0 \%$ & \multicolumn{2}{|c|}{$63.6 \%$} \\
\hline $23.8 \%$ & \multicolumn{2}{|c|}{$63.7 \%$} \\
\hline $8.1 \%$ & \multicolumn{2}{|c|}{$60.0 \%$} \\
\hline $12.9 \%$ & \multicolumn{2}{|c|}{$62.8 \%$} \\
\hline $8.5 \%$ & \multicolumn{2}{|c|}{$59.3 \%$} \\
\hline $18.2 \%$ & \multicolumn{2}{|c|}{$63.5 \%$} \\
\hline $38.4 \%$ & \multicolumn{2}{|c|}{$54.5 \%$} \\
\hline $8.4 \%$ & \multicolumn{2}{|c|}{$53.9 \%$} \\
\hline $7.1 \%$ & \multicolumn{2}{|r|}{$51.3 \%$} \\
\hline
\end{tabular}

Figure 1: Rating of national issues.

The survey results further indicate that public transport was by far the highest priority issue in transport in South Africa today. This is illustrated in Figure 2. Almost $20 \%$ of the respondents highlighted public transport as their main concern. If the researchers considered public transport as being inclusive of all taxi related issues, public transport would have been selected as a priority issue by $31 \%$ of respondents.

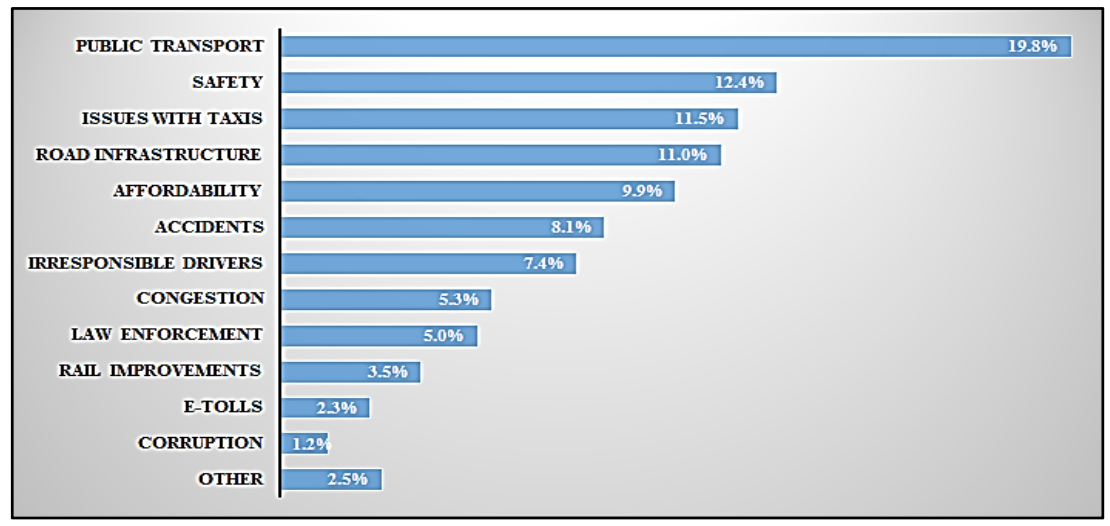

Figure 2: Highest transport issues.

Respondents were asked to give their opinion on what they considered to be the most pressing transport issues in the country. Responses grouped under the term "public transport" included generic mentions of the term "public transport" as well as specific responses related primarily either to the quantity or quality of public transport "Safety" includes any mentions of the generic term "safety" as well as specific mentions of personal safety when using public transport, road safety and vehicle conditions. "Issues with taxis" included any mentions of the generic term "taxis" or "taxi services" as well as other more specific terms such 
as quality of taxi equipment, reckless taxi drivers, taxi violence, un-roadworthy taxis and complaints about taxi associations.

"Road infrastructure" includes any mentions of the generic term "quality of roads" as well as specific mentions of potholes and road maintenance. "Affordability" includes mentions that public transport is too expensive, high increases in transport costs, and too high fuel costs. Other priority aspects that were mentioned were high number of road accidents, irresponsible drivers, high levels of congestion in urban areas, need for improved and stricter law enforcement (e.g. higher number and more visibility of law enforcement officers), the need for improved rail services and dissatisfaction with e-tolls.

In a broader context, respondents were asked to rate the conditions of selected transport facilities and services, i.e. BRT, taxis, buses and rail services, roads and congestion. Only a relatively small percentage of respondents are of the opinion that transport facilities and services are in excellent condition, with bus services (specifically BRT services) providing the highest rated public transport service (see figure 3). The opinions concerning the overall condition of transport facilities and services, supports the public's sentiments regarding the highest transport priorities in South Africa (as shown in figure 2).

\begin{tabular}{|c|c|c|c|c|}
\hline Condition of transport areas & Rating & $\begin{array}{c}\text { Very Poor } \\
0-20\end{array}$ & $\begin{array}{c}\text { Trififierent } \\
30-80\end{array}$ & $\begin{array}{l}\text { Excellent } \\
90-100\end{array}$ \\
\hline Bus Rapid Transit & 62.0 & $16.9 \%$ & $49.5 \%$ & $35.6 \%$ \\
\hline Bus services & 58.1 & $20.0 \%$ & $630.6 \%$ & $26.4 \%$ \\
\hline Minibus taxis & 55.3 & $25.6 \%$ & $510 \%$ & $22.5 \%$ \\
\hline Condition of roads & 52.2 & $27.6 \%$ & $47.8 \%$ & $24.7 \%$ \\
\hline Passenger rail services & 49.3 & $29.8 \%$ & solswo & $193 \%$ \\
\hline Road congestion & 48.5 & $34.9 \%$ & 498 & $15.7 \%$ \\
\hline
\end{tabular}

Figure 3: Condition of transport areas.

When tested on the current state of local transport, only $23 \%$ of the respondents felt that transport in their local area was much better now than a year ago, whilst almost $77 \%$ either felt that there was very little change or that it was much worse than a year ago. Respondents that indicated that transport in their local area was worse than a year ago, attributed this primarily to the quality of roads and transport, high transport costs and the lack of sufficient levels of public transport. This is reflected in Figure 4.

Considering the future state of transport in South Africa, only 32\% and 34\% of the respondents, respectively, were of the opinion that transport would be much better nationally and in their local area. Nearly $50 \%$ of the respondents were indifferent to whether transport would improve, either locally or nationally.

Asked on the frequency of public transport usage, the regular public transport users (4-7 times a week) clearly indicated that taxis are the dominant mode of transport, followed by buses. The same is also true for commuters who use public 
transport 2-3 times a week. For public transport users that commute less frequently, buses become the dominant mode.

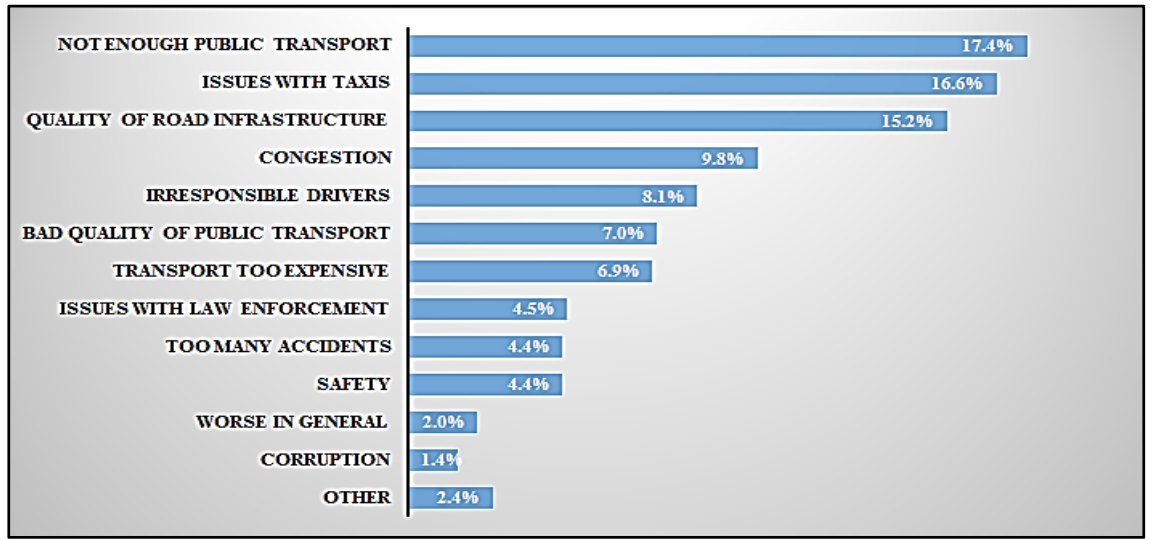

Figure 4: Reasons for worsening of local transport.

Nearly $50 \%$ of the respondents indicated that they have never used trains, which is expected given the current commuter rail coverage. However, $81 \%$ of the respondents indicated that they have used taxis as a form of transport at some time. The public transport travel patterns for the STOPSA 2015 survey is very comparable to the latest National Household Travel Survey [12], which indicate that $68 \%$ of public transport trips are made by taxi, $19 \%$ by bus and $13 \%$ by train. Very few respondents indicated that they have never used any form of public transport at all.

Table 1: $\quad$ Public transport usage.

\begin{tabular}{|l|c|c|c|c|}
\hline \multicolumn{1}{|c|}{ Public transport usage } & Taxi & Gautrain * & Train & Bus/BRT \\
\hline 4 to 7 times a week & $75.9 \%$ & $0.7 \%$ & $6.7 \%$ & $17.5 \%$ \\
\hline 2 to 3 times a week & $69.6 \%$ & $1.8 \%$ & $11.1 \%$ & $19.3 \%$ \\
\hline Once a week & $\mathbf{5 0 . 7} \%$ & $1.1 \%$ & $14.5 \%$ & $34.8 \%$ \\
\hline Once every 2 weeks & $\mathbf{4 6 . 3 \%}$ & $1.4 \%$ & $19.4 \%$ & $34.3 \%$ \\
\hline Once a month & $36.1 \%$ & $5.8 \%$ & $20.8 \%$ & $43.1 \%$ \\
\hline Less than once a month & $21.1 \%$ & $\mathbf{8 . 0} \%$ & $33.8 \%$ & $45.1 \%$ \\
\hline Never Use & $18.7 \%$ & $\mathbf{8 1 . 2} \%$ & $45.1 \%$ & $36.2 \%$ \\
\hline
\end{tabular}

* Only Gautrain usage data for Gauteng province included

When considering all regular transport use (4-7 times a week), including private car, public transport and non-motorised transport, it is evident that private cars are still the dominant form of transport in the country. Approximately $48 \%$ of regular trips are made by private cars, whilst only $10 \%$ of these trips are made 
using public transport provided by government (buses and trains). A very high $41 \%$ of respondents indicated that walking was their main mode of transport, whilst a very low $2 \%$ of respondents indicated that they cycled regularly. Most of respondents $(91 \%)$ indicated that they would never use cycling as their main mode of transport.

The findings firstly indicate the continued high use of private motor vehicles as the dominant form of regular transport. Taxis, which are essentially provided by the private sector, dominate the "public" transport modes, while buses and trains only move a small portion of the regular transport market. Cycling remains a much underutilised mode whilst walking forms a part or the whole of a large proportion of commuters' daily trips.

\section{Conclusion}

The White Paper on National Transport Policy 1996 highlights in its mission for land passenger transport, the need for safety, reliability, efficiency, effectiveness, co-ordination, integration, accountability, mobility and accessibility. The vision for transport in South Africa requires that this incorporates both operations and infrastructure and must be done in a way that is environmentally and economically sustainable.

Most of these issues are reiterated in 2012's National Development Plan, which highlights the need to invest in transport infrastructure and improve public transport. Key to this is the future focus areas for transport investment, which should aim at empowering South Africans (economic and social development), providing safe, affordable, reliable means of mobility as well as providing environmentally friendly transport alternatives.

NATMAP 2050's objectives include providing an improved sustainable public transport system, with better and safer access, more frequent and better quality services and facilities. It should also deliver greater mobility options particularly for those who do not have a car and focus some investment efforts on developing a non-motorised transport network. Finally, it is anticipated that the transport system should charge the traveller a fair reflection of the costs of making a journey financially, socially and environmentally.

The State of Transport Opinion Poll SA clearly highlights that transport is a major issue amongst South African citizens. By rating it as the third highest priority in the country, South Africans are indicating that the current transport system does not meet their current needs. When considering the highest priority issues in transport in South Africa, public transport is clearly an issue for a very high percentage of respondents. This included aspects related to quality, frequency and amount of services, travel times, etc.; issues that relate to customer service and mobility and accessibility. Other aspects that are highlighted are affordability, quality of infrastructure and safety.

It is evident from the comparison between the survey results and the overview of the salient points of the current public transport policy that policy is, in fact, relatively strongly aligned with the public transport needs of the South African population. The findings seem to indicate that, while aspects that concern South 
Africans such as mobility, accessibility, affordability and safety have been prioritised in policies since 1996, these concerns have not been addressed, as is evidenced by the repetition of similar priority issues in the National Development Plan and in NATMAP 2050.

Despite the synergies between public requirements and public policy, it is evident that much of the societal needs remain unaddressed. The policy highlights the need for sustainable, environmentally friendly solutions, which do not appear to be being addressed, as is evidenced by the continued high motor vehicle usage, the low levels of uptake on government subsidised public transport and the relative lack of support for non-motorised transport solutions. Whilst government has recently invested in cycling infrastructure, these solutions have clearly not yet addressed the anti-cycling sentiment in the urban commuting environment.

With regards to public transport, the relative lack of support for government subsidised modes is underpinned by the commuters' perception of the poor quality of services, particularly in regards to frequencies, accessibility and overall quality. Commuters tend therefore to opt for the more flexible mode, taxis, but have major concerns regarding service levels and safety. Law enforcement also remains a critical issue in providing a safe and reliable commuting environment.

Commuters have clearly highlighted affordability as one of their most pressing transport issues. Whether the current policy, with its focus on charging the traveller a fair reflection of the costs, will alleviate the burden on the commuter is debatable.

The comparison between the opinions of the public and transport policy has clearly indicated that some of the objectives are unlikely to meet the needs of the commuting public in urban areas in South Africa. On the other hand, many of the policy objectives are aligned with the needs of the public, but, despite this being entrenched in public policy for 20 years, have not yet being addressed. As such, public transport requires more than appropriate policies but also a resolute political commitment to policy implementation.

\section{References}

[1] Oldendick, R. W., The Role of Public Opinion in Policy and Practice, USC Institute for public service and policy research: Columbia, pp. 29-35, 2002.

[2] Republic of South Africa, Constitution of the Republic of South Africa. Act 108 of 1996. Government Printers: Pretoria, 1996.

[3] IDASA, Africacheck. www.africacheck.org/factsheets/guideunderstanding-and-reporting-on-opinion-polls/

[4] Lee, T. \& Odugbemi, S., Accountability through Public Opinion: From Inertia to Public Action, World Bank:Washington DC, 2011.

[5] Levasseur, D. G., The role of public opinion in policy argument: an examination of public opinion rhetoric in the federal budget process. Argumentation and advocacy, 43(1), p. 152, 2005.

[6] Chudowskya, V. \& Kuziob, T., Does public opinion matter in Ukraine? The case of foreign policy. Communist and Post-Communist Studies, 36(3), pp. 273-290, 2003. 
[7] Lewis, C. W. \& Hildreth, W. B., Budgeting: Politics and Power, $2^{\text {nd }}$ ed., Oxford University Press:New York, 2012.

[8] Geer, J. G., Schiller, W. J., Herrera, R. \& Segal, J. A., Gateways to Democracy: An Introduction to American Government, $3^{\text {rd }}$ ed., Cengage Learning: Boston, 2015.

[9] Hensher, D. \& Daniels, R., Monitoring community views on transport confidence over time: the quarterly TOPS Survey. www.atrf11.unisa.edu.au /Assets/Papers/ATRF110009final.pdf

[10] Sophism, Y., The Role Of Public Opinion Polls In Our Emerging Democracy. www.modernghana.com/news/113800/1/ the-role-of-publicopinion-polls-in-our-emerging-d.html

[11] Department of Transport, Key findings of the NHTS, www.arrivealive.co.za/document/household.pdf

[12] Statistics South Africa, National Household Travel Survey: February to March 2013, StatsSA: Pretoria, 2014.

[13] The World Bank, Connecting to Compete 2014: The LPI and Its Indicators, The World Bank Washington, 2014.

[14] Friedman, S., Service delivery isn't the problem, www.ru.ac.za/perspective/ perspectivearticles/name, 74203,en.html

[15] Raghavan, S., South Africa loses faith with the ANC, www.independent.co.uk/news/world/africa/south-africa-loses-faith-withthe-anc-8303778.html

[16] Department of Transport,. White Paper on National Transport Policy, Department of Transport: Pretoria, 1996.

[17] Urban LandMark, Strategies to help poor people access urban land markets, www.urbanlandmark.org.za/downloads/tm 2011 01.pdf

[18] National Planning Commission, NDP 2030: Our future - make it work, Republic of South Africa:Pretoria, 2012.

[19] Department of Transport, NATMAP 2050: National Transport Master Plan Synopsis Update, Department of Transport: Pretoria, 2015.

[20] Statistics South Africa, Census 2011, Statistics South Africa: Pretoria, 2012.

[21] Luke, R. \& Heyns, G. J., Public transport policy and performance: the results of a South African public opinion poll. Journal of Transport \& Supply Chain Management,, 7(1), pp. 1-8, 2013. 